2019

\title{
The Sons Report (1989-1994, Mathematical Association of America): The Way It Was
}

Linda R. Sons

Northern Illinois University, Isons@niu.edu

Follow this and additional works at: https://digitalcommons.usf.edu/numeracy

Part of the Curriculum and Instruction Commons, Higher Education Commons, and the Mathematics Commons

\section{Recommended Citation}

Sons, Linda R.. "The Sons Report (1989-1994, Mathematical Association of America): The Way It Was." Numeracy 12, Iss. 1 (2019): Article 12. DOI: https://doi.org/10.5038/1936-4660.12.1.12 


\title{
The Sons Report (1989-1994, Mathematical Association of America): The Way It Was
}

\author{
Abstract \\ Recollections and commentary by Linda R. Sons on a 1994 national report entitled Quantitative \\ Reasoning for College Graduates: A Complement to the Standards. Professor Sons chaired the \\ committee which wrote the report and championed its use. \\ This paper traces the development of the 1994 MAA report Quantitative Reasoning for College Graduates: \\ A Complement to the Standards--a report which is still surprisingly relevant. The paper highlights some \\ major parts of the report, describing the context in which its conclusions were made. Additionally, it \\ challenges and encourages those continuing the quest for QL in the nation by noting progress made since \\ 1989 and two avenues (the NNN and the SIGMAA QL) through which pursuits can be shared and ideas \\ exploited.

\section{Keywords} \\ quantitative reasoning, quantitative literacy, MAA-CUPM \\ Creative Commons License

\section{(c) (i) (8)} \\ This work is licensed under a Creative Commons Attribution-Noncommercial 4.0 License

\section{Cover Page Footnote} \\ Linda R. Sons is an emerita Distinguished Presidential Teaching Professor of Mathematical Sciences at \\ Northern Illinois University. She is the recipient of teaching awards from the Illinois Section of the \\ Mathematical Association of America and from the Illinois Council of Teachers of Mathematics. She \\ served on many major national committees of the Mathematical Association of America and has \\ authored over 50 research articles in mathematics (complex analysis) and mathematics education.
}


Preface: For over 100 years the Mathematical Association of America (MAA) has been the leading professional association in collegiate mathematics in the United States. Recommendations of its Committee on the Undergraduate Program (CUPM) have shaped the curriculum for the undergraduate major in mathematics and provided guidance for issues related to mathematics for nonmajors as well. The major professional organization concerned with mathematics education in the nation's schools has been the National Council of Teachers of Mathematics (NCTM). Originally published in 1989, and in revised form in 2000, the NCTM's Principles and Standards for School Mathematics (often shorthanded to The Standards) states the essential components of a highquality school mathematics program for each and every student from prekindergarten through grade 12. ${ }^{1}$ The report discussed here is a product of CUPM, and its title purposefully connects to The Standards of the NCTM.

\section{The Way It Was...}

THIS report was different-deliberately so. It was not a mild-mannered, fullcolor document with side bars to attract your attention. Instead, it was a straightforward address to those in higher education, and especially those in the collegiate mathematics community with recommendations which would mesh with the NCTM school standards and which could be realistically achievable in the college years. It said the mathematics community at colleges and universities should take some responsibility for actions to change the sorry state of mathematics competency, not just bemoan it.

The year was 1989, and the time was ripe for change in mathematics education in the nation. A series of national reports regarding education were in the public eye (among these, A Nation at Risk ${ }^{2}$ and Everybody Counts ${ }^{3}$ ). The NCTM had been working for change in the elementary and high schools with the publication of An Agenda for Action, ${ }^{4}$ and then The Standards. The MAA through its CUPM, long the voice for mathematics in the undergraduate college program, sought to provide some suggestions to colleges and universities to deal with the sorry state of general mathematical knowledge among the American people. A subcommittee of CUPM was formed to address the question of what quantitative literacy requirements should be established for all students who receive a bachelor's degree. I was asked to chair the subcommittee because we at Northern Illinois University had just finished a thorough review of what a bachelor's degree from NIU meant, and, among other conclusions, arrived at a set

\footnotetext{
${ }^{1} \operatorname{NCTM}(1989,2000)$

${ }^{2}$ National Commission of Excellence in Education (1983)

${ }^{3} \mathrm{NRC}(1989)$

${ }^{4} \operatorname{NCTM}(1980)$
} 
of minimal competencies for all students, which included a minimal competency in mathematics. I knew the task would not be easy, but it could be of value for the nation.

In 1989, I remembered my experience at NIU in 1984. We had had to convince a university-wide committee that a minimal competency in mathematics for all college students should be adopted. We were convinced it was essential for the college educated, especially since they would be leaders in our nation. A colleague and I posed some natural problems which could arise for a citizen and presented them to the university committee; they approved the competency while recognizing the difficulty of the problems. We were then faced with preparing a course to address the competency and found ourselves having to write a textbook for the course since there were none available at the time. As I continued work on the course, I became even more convinced that it was in our national interest to address QL requirements for all seeking a baccalaureate degree.

In response to its charge, the subcommittee of CUPM went to work with the hope of preparing a report that was visionary, usable, and realistic. Some people outside the committee wanted the report to be a distillation of the existing situation, and some wanted validation of what they were already doing or what their admissions already required. Textbook publishers and those who wrote liberal arts mathematics books wanted their existing products to meet the standards the committee would describe. Mathematicians did not want to derail the well-established path to calculus instruction-every college student should march up and take college algebra and, through that experience, develop manipulative skills so as to not have a barrier to their study of calculus. Further, while mathematics faculty were happy to teach (which, back then, meant lecture) a liberal arts course with their favorite topics, they did not want to teach a quantitative literacy course viewed as too low-level for them (and, alas, some recognized it demanded real teaching, which would be time consuming in preparation and student contact).

As a massive study undertaken by the QL subcommittee determined, most colleges and universities had a mathematics requirement prescribed or implied for their students pursuing a bachelor's degree, but it seldom had a stated purpose for the requirement. It often consisted of simply having the student choose a course from a list of six or so, while some highly selective colleges required a liberal arts course. There was no real concern for quantitative literacy. But, in some states legislative action brought a desire for mathematics faculty to have a national organization to give a guideline that would correct impositions being made on them-such as in Mississippi where the state legislature mandated all public university students take college algebra (and, indeed, some "creative" college algebra courses emerged). 
The QL subcommittee did a lot of homework. Not only did our members study and discuss the past MAA reports and all the national reports (more of which kept coming out), but they conducted discussion sessions at national mathematics meetings (and section meetings) to air out the attitudes and mindsets prevalent in the mathematics community. Some committee members also went to meetings of the American Association for the Advancement of Science, the American Statistical Association, professional associations in the sciences and in other disciplines, and entered into discussions with political groups in their states. (Some states concerned with the number of students taking remedial courses in college set a requirement that universities not be allowed to teach such courses, and those needing them should go to community colleges for such study.) A heated debate at a national meeting was attended by some 200 arguing as to whether College Algebra should be defined as determining quantitative literacy for all baccalaureate students.

Debates raged over whether there was a real difference between the term "quantitative literacy" and "some significant proficiency in mathematical thinking and in the most useful elementary techniques that go with it." The term "numeracy" was seen as manipulating numbers without involvement in problem solving. ${ }^{5}$ The committee adopted the point of view that QL concerns mathematics broadly understood.

\section{A Closer Look ${ }^{6}$}

And so Part One of the report addressed the question, "Why Quantitative Literacy?" We listed nine principal reasons why it would be a good thing if we could expect educated people to be quantitatively literate (Table 1).

\footnotetext{
${ }^{5}$ Obviously, not the view of NNN or Numeracy (ed.)

${ }^{6}$ The Report is available as an html document on the MAA website: https://www.maa.org/. On the home page, enter "quantitative literacy" in the search box at the upper right corner. The report currently (Sept 2,2018) comes up as the second in a list of 128 results, with the explanation: This Report, originally published in 1994, reflects some of the earliest efforts to reshape the notion of quantitative literacy for a rapidly-growing, and substantially changing, student body. While much work has been done since, we have maintained the report to provide insight into the development of more-recent quantitative literacy/numeracy efforts. The actual link to the report is: https://www.maa.org/programs/faculty-and-departments/curriculum-department-guidelinesrecommendations/quantitative-literacy/quantitative-reasoning-college-graduates
} 
Table 1.

Nine Reasons

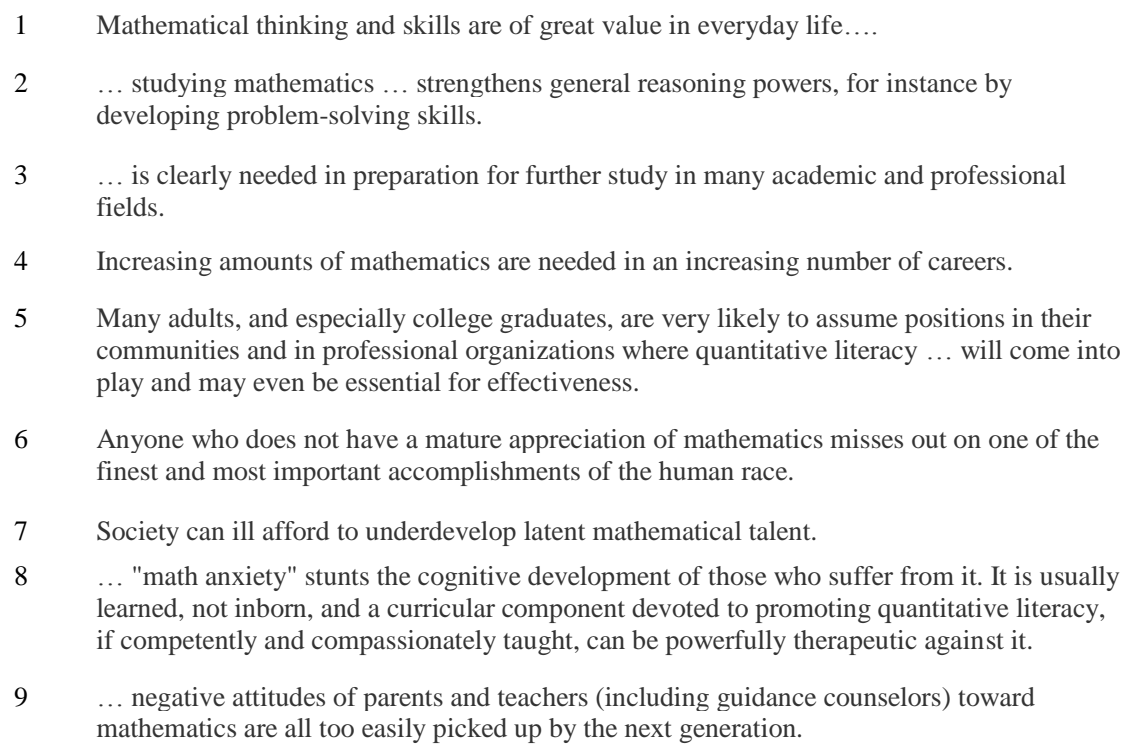

Part Two of the report, termed "Quantitative Literacy: Goals," set out to describe what, specifically, should be expected of a college graduate. It states in very clear language:

In short, every college graduate should be able to apply simple mathematical methods to the solution of real-world problems.

In my view, since the time of the report, that one short sentence articulates what has become the most widely adopted definition of QL for college students. The report, in the same paragraph, expands on the capabilities inherent in this simple concept (Table 2).

Table 2.

Five Goals

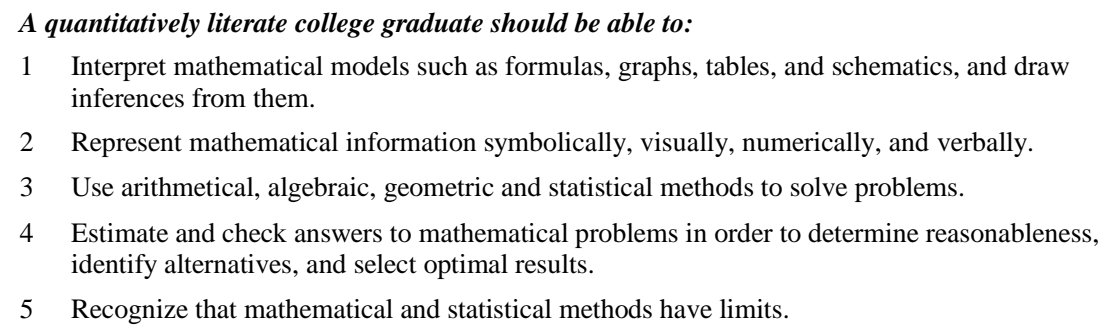

It was readily understood that such learning encompassed learning in context and that a single college course could not accomplish the intended goals. And so came the cry: 
...mathematics must permeate the undergraduate experience the same way it permeates modern society: Mathematics Across the Curriculum,

and "Mathematics Across the Curriculum" became a subheading in Part III, "Actions and Strategies" (Table 3). Under the next subheading, we advocated a "foundation" course or experience together with some continuing experience which used the foundation base.

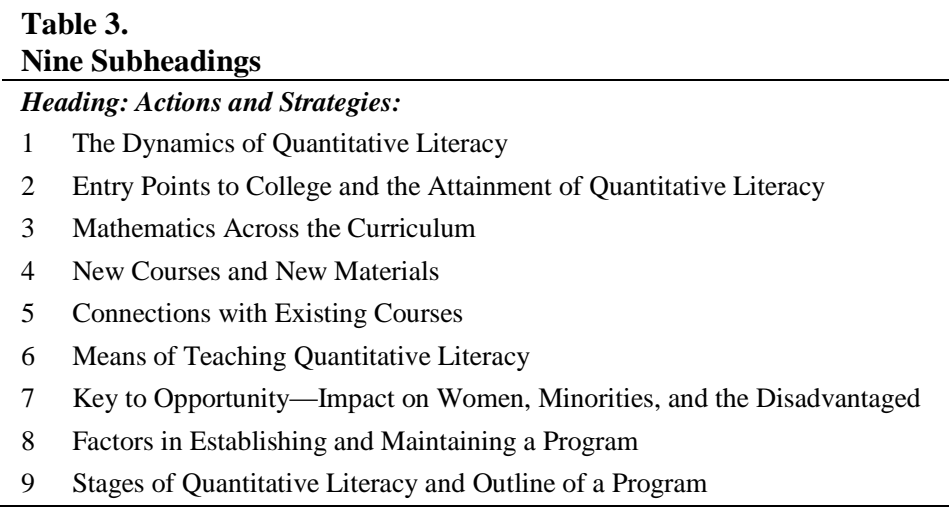

Overall, the report emphasized the collegiate responsibility for QL education "as a thoroughly legitimate and even necessary goal for baccalaureate graduates." Further, knowing no action in a collegiate setting would occur without some specific group being challenged to do so, the subcommittee concluded mathematics departments should supply the needed leadership. Part III was thus written "to offer answers to questions likely to be raised by those serious about establishing a quantitative literacy program." Finally (Part IV), the report recommended regular assessments of QL programs once established. Thus the roadmap in the ca. 20 paragraphs of Part IV starts with:

The establishment of a quantitative literacy program is expected to go hand-in-hand with an attendant assessment procedure. By assessment procedure we mean an explicit means for obtaining information on the program's impact on student development.

As presented to CUPM, the QL report was detailed and lengthy. In addition to the four parts of the main report, appendices included an annotated bibliography (35 references), a list of topics on which one might base a reasonable syllabus, brief descriptions of eight already existing foundations courses, a sample instrument for assessing student attitudes toward mathematics, a list of problems related to minimal competency, and two project ideas. Some CUPM members and some colleagues in the hierarchy of the MAA wanted to excise large parts of the report. The topical listing (Table 4) in the report's appendix was viewed as too minimal by some critics who ignored the expression "laced with good applications" in the statement that introduced the list. In bringing the CUPM- 
adopted report to the MAA Board of Governors, Jim Leitzel (Chair CUPM, 19911995) called special attention to the report's appendices.

Table 4

Twenty-Four Topics*

Arithmetic

- Estimation.

- Percentage change.

- Use of calculator: rounding and truncation errors; order of operations.

Geometry

- Measurement: units and conversion of systems; length; area; volume.

- "Familiar" shapes: rectangles, triangles, circles, cones, cylinders, spheres, the Pythagorean relationship.

- Angles: slopes of lines; parallel and perpendicular lines; right angles; similarity.

- Complex shapes: approximation by "familiar" shapes; solution region for a system of linear inequalities in the plane.

\begin{tabular}{|c|c|}
\hline $\begin{array}{c} \\
\text { Algebra } \\
\bullet \\
\bullet\end{array}$ & $\begin{array}{l}\text { Linear equations: equations of one unknown; systems of two unknowns; methods of solution. } \\
\text { Proportionality. } \\
\text { Graphs and tables: construction, reading, interpreting; extrapolating from; the notions of direct } \\
\text { and indirect variation. } \\
\text { Simple exponents: roots and powers; products and quotients with a common base. } \\
\text { Concept of function: constructing discrete and continuous functions; graphical representation of } \\
\text { functions; zeros of functions. }\end{array}$ \\
\hline Statistics & $\begin{array}{l}\text { Experimental probability: counting; mutually exclusive and independent events. } \\
\text { Graphical displays of data: pie and bar charts; frequency polygons; visual impact of scale } \\
\text { changes. } \\
\text { Central tendency and spread: Comparison of data sets using mean, median, mode and standard } \\
\text { deviation, quartile deviation, range; percentile rank. } \\
\text { The idea of correlation: measuring and evaluating the relationship between two variables. } \\
\text { Common sources of error: sampling error, misinterpreting averages or probabilities; invalid } \\
\text { comparison distributions; statistical significance; statistical "proof". } \\
\text { Random sampling: the count-recount technique; polls; lotteries; fair representation. } \\
\text { Linear fit: comparison of fit of two lines to a data set. } \\
\text { Quality control: the binomial distribution } \\
\text { Simulation }\end{array}$ \\
\hline Other & $\begin{array}{l}\text { Exponential change } \\
\text { Rates: Comparison of average rates of change } \\
\text { Optimization: The notions of maxima and minima of functions with or without constraints; } \\
\text { graphical and computational methods of finding them; simple analytic methods, such as } \\
\text { completing the square for quadratic polynomials. }\end{array}$ \\
\hline
\end{tabular}

\section{Downstream}

Having raised awareness of QL needs through the meetings held in preparation of the report, there were those waiting to use it when CUPM adopted it. Further, subcommittee members set out to publicize the report by taking advantage of the MAA's introducing the concept of a special interest group within the MAA structure, termed a SIGMAA. A QL SIGMAA was one of the first such groups 
formed. Through that SIGMAA each national meeting of the MAA has since had some programming concerning QL issues.

As a means for continuing to encourage the development of QL programs, a proposal was made to the MAA publications board to publish a volume on current practices which led to the MAA Notes volume \#70. ${ }^{7}$

After the QL report was adopted, the College Board under Robert Orrill in the Office of Academic Affairs, with the support from the Pew Charitable Trusts founded and directed the National Council on Education and the Disciplines (NCED) whose goal was to promote discussion about core literacies at the transition from secondary to postsecondary education. ${ }^{8}$ In cooperation with the National Research Council and the MAA, NCED hosted a national forum on quantitative literacy at the National Academy of Sciences in Washington, DC. ${ }^{9}$ The National Numeracy Network (NNN) began in 2000-2001 ${ }^{10}$ as an outreach component of the NCED initiative in quantitative literacy. The NNN formally became a member organization in 2004. Some ten years ago the NNN established the journal Numeracy, which provides dialogue, help, and encouragement for those working with QL. ${ }^{11}$

\section{Reflection}

For me, it has been gratifying to have had many telling me of their use of the QL report in formulating programs on their campuses. The definition of QL in the report has been widely adopted and understood. Major changes have come in textbooks since the report was written (as noted in the report, materials for a genuine QL course were likely to be short-lived because they need to be current with the world as it is being lived). Even College Algebra texts now have problems and exposition more QL in nature.

Assessment is still a knotty problem with mathematicians (and others) continuing to want a kind of linear notion of levels of QL-standards of what constitutes QL at different ages and educational levels along with strategies as to how these can be assessed. Those admitted to Ivy League schools may not be QL, and those completing AP calculus courses also may not be QL. More mathematics education research is still needed to assess the complexities of problem solving taking into account the development of the human mind right up through the college years (and beyond to age 26 or so?). A good question is what

\footnotetext{
${ }^{7}$ Gillman (2006)

${ }^{8}$ Steen $(2001,2004)$; see also Madison and Steen (2008)

${ }^{9}$ See Madison and Steen (2003)

${ }^{10}$ Madison and Steen (2008)

${ }^{11}$ Vacher (2017)
} 
triggers "control" in problem solving wherein knowing relevant mathematics is connected with a problem and used to provide a solution or estimate one.

Despite some obvious dating of material in places, it is perhaps surprising to see how relevant the 1994 QL report still is. In reading articles appearing in journals today, I often reflect that the report speaks to issues stated therein. It seems the 1989 subcommittee did produce a report that was visionary, usable, and realistic.

\section{References}

Gillman, R., ed., 2006. Current Practices in Quantitative Literacy MAA Notes \#70. Washington, DC: Mathematical Association of America.

National Commission on Excellence in Education. 1983. A Nation at Risk: The Imperative for Educational Reform. U. S. Government Printing Office

Madison, Bernard L. and Lynn Arthur Steen, eds. 2003. Quantitative Literacy: Why Numeracy Matters for Schools and Colleges. Princeton, NJ: National Council on Education and the Disciplines.

Madison, Bernard L. and Steen, Lynn Arthur (2008) "Evolution of Numeracy and the National Numeracy Network," Numeracy, 1(1): Article 2. https://doi.org/10.5038/1936-4660.1.1.2.

NCTM (National Council of Teachers of Mathematics). 1980. An Agenda for Action: Recommendations for School Mathematics of the 1980s. Reston, VA: National Council of Teachers of Mathematics.

1989. Curriculum and Evaluation Standards for School Mathematics. Reston, VA: National Council of Teachers of Mathematics.

2000. Principles and Standards for School Mathematics. Reston, VA: National Council of Teachers of Mathematics.

NRC (National Research Council). 1989. Everybody Counts: A Report to the Nation on the Future of Mathematics Education. Washington, DC: National Academy Press.

Sons, L. R., ed., 1994. Quantitative Reasoning for College Students: A Complement to the Standards. Washington, DC: Mathematical Association of America.

Steen, L.A., ed., 2001. Mathematics and Democracy: The Case for Quantitative Literacy. Princeton, N.J.: The National Council on Education and the Disciplines.

2004. Achieving Quantitative Literacy: An Urgent Challenge for Higher Education. Washington, DC: Mathematical Association of America.

Vacher, H. L. 2017. "Ten Years, Twenty Issues, and Two Hundred Papers of Numeracy: Toward International Reach and Transdisciplinary Utility." Numeracy, 10 (2): Article 1. https://doi.org/10.5038/1936-4660.10.2.1. 